\title{
Responses of nitrogen metabolism to copper stress in Luffa cylindrica roots
}

\author{
L.-1. Zhang ${ }^{1}$, X.-j. He ${ }^{1 *}$, M. Chen ${ }^{1}$, R.-d. An ${ }^{1}$, X.-1. An ${ }^{2}$ and J. Li ${ }^{1}$ \\ ${ }^{1}$ Institute of Ecology and Environment, State Key Laboratory of Hydraulics and Mountain River Engineering, College of Water \\ Resources and Hydropower, Sichuan University, Chengdu 610065, China. ${ }^{2}$ College of Life Sciences, Sichuan University, 610064, \\ Chengdu, China. "Corresponding author: xiaojia25@gmail.com
}

\begin{abstract}
Pot experiments were performed to investigate the responses of nitrogen metabolism to copper stress in Luffa cylindrica roots. Four treatments were used, in which varying copper concentrations $(25,50,75$ and $100 \mu \mathrm{M})$ were added to MS medium. The fresh weights of the roots decreased gradually with the increasing copper concentrations. At the lower concentrations, the ammonium and nitrite levels increased compared with the control, but the nitrate concentrations significantly decreased with 75 and $100 \mu \mathrm{M}$ copper. Compared with the control, nitrate reductase activity levels gradually increased with increasing copper concentrations of up to $50 \mu \mathrm{M}$, and nitrite reductase activity levels significantly decreased. Copper stress led to variable increases in the activities of glutamine synthetase and glutamate synthase compared with the controls. The NADH- glutamate dehydrogenase (NADH-GDH) and NADglutamate dehydrogenase (NAD-GDH) activities were affected by the copper treatments, but that of NAD-GDH was significantly reduced by $100 \mu \mathrm{M}$ copper. The activities of alanine aminotransferase (AlaAT) and aspartate aminotransferase (AspAT) showed varying changes following the copper treatments. The present results indicate that Luffa cylindrica shows altered activities of enzymes associated with nitrogen metabolism during copper stress, enabling it to monitor and adapt to changes in its $\mathrm{N}$ status and supply, thereby minimizing the harmful effects of the stress.
\end{abstract}

Keywords: Nitrogen metabolism, Luffa cylindrica, copper stress, nitrogen-assimilating enzymes

\section{Introduction}

Copper $(\mathrm{Cu})$ is an essential element for plant growth that plays a significant role in many physiological processes, including photosynthesis, respiration, carbohydrate distribution, nitrogen fixation, protein metabolism, cell wall metabolism and hormone perception. Plants typically find ample supplies of copper in the soil, but high concentrations of copper can be a stress factor triggering physiological responses including the inhibition of plant growth, the production of reactive oxygen species (ROS) and alterations in enzymatic and non-enzymatic antioxidant activities (Gao et al., 2008; Yruela, 2009). Moreover, copper stress may result in altered nitrogen $(\mathrm{N})$ metabolism-related activities, including ion uptake, $\mathrm{N}$ assimilation, and amino acid and protein synthesis (Xiong et al., 2006; Azmat and Khan, 2011). In plants, the response of $\mathrm{N}$ metabolism to copper stress has been extensively studied because of the importance of understanding the behavior of $\mathrm{N}$ 
metabolism-associated enzymes in the presence of highly toxic metals.

$\mathrm{N}$ plays important roles in plant growth and development, and its metabolism affects all levels of plant function. However, $\mathrm{N}$ metabolism requires a complex series of biochemical reactions. For example, in nitrate assimilation, the nitrate is converted to $\mathrm{NO}_{2}^{-}$by nitrate reductase (NR), and $\mathrm{NO}_{2}{ }^{-}$is converted to $\mathrm{NH}_{4}-\mathrm{N}$ by nitrite reductase $(\mathrm{NiR})$. The resulting $\mathrm{NH}_{4}-\mathrm{N}$ is then assimilated into amino acids and other metabolites through the combined actions of glutamine synthetase (GS) and glutamate synthase (GOGAT) in addition to glutamate dehydrogenase (GDH), alanine aminotransferase (AlaAT) and aspartate aminotransferase (AspAT) (Stitt et al., 2002; Mokhele et al., 2012). Previous studies have shown that high concentrations of copper in plants lead to significant changes in $\mathrm{N}$ metabolism, including the inhibition of the uptake and transportation of nitrate and the regulation of NR and NiR activities (Xiong et al., 2006; Azmat and Khan, 2011). Moreover, the GS-GOGAT cycle and GDH pathways in some plant species have been shown to be significantly induced by copper treatment, reflecting a general disorder of $\mathrm{N}$ assimilation (Ludewig et al., 2007). These findings have increased the understanding of the behavior of $\mathrm{N}$ metabolism-associated enzymes and the regulation of $\mathrm{N}$ metabolism under copper stress.

Luffa cylindrica L., which is commonly known as the sponge gourd, is cultivated in tropical and subtropical Asia regions and consumed daily by the population. The seeds and sponges of the old fruits are also used in traditional Chinese medicine as anthelmintics, stomachics, and antipyretic phytomedicinal drugs (Yang et al., 1999). Although there have been many studies assessing the effects of heavy metal stresses on physiological and defense responses in Luffa cylindrica ( $\mathrm{He}$ and $\mathrm{Li}, 2010$ ), the effects of copper on $\mathrm{N}$ metabolism have not been studied in this plant. Therefore, to assess the copper stress-induced effects on $\mathrm{N}$ metabolism in Luffa cylindrica roots, in vitro cultures were established using embryos, and the germination patterns and culture characteristics were observed and analyzed under copper stress. Furthermore, the concentrations of various forms of $\mathrm{N}$ and the activities of $\mathrm{N}$-assimilating enzymes were evaluated in relation to varying copper concentrations.

\section{Materials and Methods}

\subsection{Embryo germination and seedling growth}

Luffa cylindrica seeds were obtained from a traditional Chinese medicine market in Chengdu, China. The seeds were separated into seed coats and were surface sterilized in $70 \%$ ethanol for $30-45 \mathrm{sec}$ followed by $0.1 \%$ mercuric chloride for $8-10 \mathrm{~min}$. The seeds were then rinsed with distilled water and soaked for $24 \mathrm{~h}$ at $25{ }^{\circ} \mathrm{C}$, and the embryos were separated from the seeds on a clean bench. The embryos were washed several times using distilled water, and three embryos each were planted in $100-\mathrm{mL}$ wide-neck bottles on aliquots of MS medium containing 0 (control), 25, 50, 75 and $100 \mu \mathrm{M}$ Copper, supplied as $\mathrm{CuSO}_{4}$. The $\mathrm{pH}$ value of the medium was adjusted to $5.9 \pm 0.1$ prior to autoclaving at $121^{\circ} \mathrm{C}$ for $15 \mathrm{~min}$ with $30 \mathrm{~g} / \mathrm{L}$ sucrose and $7.5 \mathrm{~g} / \mathrm{L}$ agar powder. The cultures were placed in a plant incubator at $25^{\circ} \mathrm{C}$ with a $12 \mathrm{~h}$ photoperiod and $80 \%$ relative humidity. The embryos were considered to be germinating when they turned yellow, which usually occurred after $24 \mathrm{~h}$ of incubation. Those that developed two cotyledons (at 7 days) were referred to as developed seedlings. The fresh weights of the roots were recorded, and they were stored at $4{ }^{\circ} \mathrm{C}$ for further analyses.

\subsection{Determination of $N$ concentrations}

The root samples were ground and homogenized in a mortar with liquid nitrogen and then extracted using 2 $\mathrm{mL}$ of redistilled water. The extracts were centrifuged $(12,000 \mathrm{rpm}, 10 \mathrm{~min})$ at $4{ }^{\circ} \mathrm{C}$, and the supernatants were used to determine the $\mathrm{N}$ concentrations. Measurements of nitrate concentrations were conducted according 
to Agbaria et al. (1996). Determinations of $\mathrm{NO}_{2}^{-}$concentrations were performed with a spectrophotometric method (Werber and Mevarech, 1978). Ammonium concentrations were assayed using the Nessler reagent (Molins-Legua et al., 2006). These results were expressed as $\mu \mathrm{g}$ per $\mathrm{g}$ fresh weight.

\subsection{Protein extractions and estimations of $N R, N i R$ and GOGAT activities}

To estimate the NR, NiR and GOGAT activities, the samples were ground using liquid nitrogen in a mortar and homogenized and extracted in $50 \mathrm{mM}$ phosphate buffer $(\mathrm{pH} 7.5,1 / 20 \mathrm{w} / \mathrm{v})$ containing 5 $\mathrm{mM}$ cysteine, $0.5 \mathrm{mM}$ EDTA and $0.5 \%$ insoluble polyvinylpyrrolidone. The extracted suspensions were collected by centrifuging at $12,000 \mathrm{rpm}$ for $10 \mathrm{~min}$ at 4 ${ }^{\circ} \mathrm{C}$ and used for further studies.

NR activity assays were performed according to Debouban et al. (2006) with slight modifications. A $1.5-\mathrm{mL}$ reaction mixture contained $0.1 \mathrm{~mL}$ of the extraction and $1.4 \mathrm{~mL}$ of $50 \mathrm{mM}$ phosphate buffer $(\mathrm{pH}$ 7.5) with $5 \mathrm{mM}$ EDTA, $7 \mathrm{mM} \mathrm{KNO}_{3}$ and $0.15 \mathrm{mM}$ $\mathrm{NADH}$. The reaction was stopped by the addition of $0.1 \mathrm{~mL}$ of $0.5 \mathrm{M}$ zinc acetate after incubation for 30 min at $30{ }^{\circ} \mathrm{C}$, and the mixture was then centrifuged at $5000 \mathrm{rpm}$ for $10 \mathrm{~min}$. The results were expressed as the amount of enzyme required to form $1 \mu \mathrm{g} \mathrm{NO}_{2}^{-}$per min per $g$ of fresh weight.

Nitrite reductase activity assays were carried out according to Losada and Paneque (1971). Each reaction tube contained $0.1 \mathrm{~mL}$ of the extraction, 0.8 $\mathrm{mL}$ of $50 \mathrm{mM}$ phosphate buffer $(\mathrm{pH} 7.5)$ with 0.4 $\mathrm{mL}$ of $2.3 \mathrm{mM}$ methyl viologen and $0.1 \mathrm{~mL}$ of 100 $\mathrm{mM} \mathrm{NaHCO}$, with $86.15 \mathrm{mM}$ sodium dithionate. After incubation for $30 \mathrm{~min}$ at $30^{\circ} \mathrm{C}$, the reaction was terminated by vigorous shaking and boiling for $1 \mathrm{~min}$. The results were expressed as $\mu \mathrm{g}$ nitrite reduced per min per $g$ of fresh weight.

GOGAT activity assays were performed according to Rachina and Nicholas (1985). A 2-mL reaction mixture contained $0.1 \mathrm{~mL}$ of the extraction and $1.9 \mathrm{~mL}$ of 50 $\mathrm{mM}$ phosphate buffer $(\mathrm{pH} 7.5$ ) with $5 \mathrm{mM} \alpha$-oxoglutaric acid, $10 \mathrm{mM}$ glutamine and $0.15 \mathrm{mM}$ NADH. The absorbance was recorded by monitoring the oxidation of NADH $\left(\varepsilon=6.22 \mathrm{mM}^{-1} \mathrm{~cm}^{-1}\right)$ at $340 \mathrm{~nm}$ for $7-10$ $\min$. The results are expressed as the enzyme required to oxidize $1 \mu \mathrm{mol}$ NADH per min per $\mathrm{g}$ of fresh weight.

\subsection{Assays for GS, GDH, AlaAT and AspAT activities}

The fresh samples were ground with liquid nitrogen and homogenized in a mortar containing $50 \mathrm{mM}$ Tris$\mathrm{HCl}$ buffer ( $\mathrm{pH} 7.5$ ) with $0.5 \mathrm{mM}$ EDTA, $1 \mathrm{mM} \mathrm{MgCl}$, $10 \mathrm{mM} \beta$-mercaptoethanol and 0.5\% PVP. After centrifugation $(12,000 \mathrm{rpm}, 10 \mathrm{~min})$, the extracted suspensions were used for the measurements of the GS, GDH, AlaAT and AspAT activity levels.

GS activity assays were performed according to Oaks et al. (1980). The reaction mixture contained $0.1 \mathrm{~mL}$ of the enzyme extract and $1.9 \mathrm{~mL}$ of Tris- $\mathrm{HCl}$ buffer (50 mM, pH 7.5) with $13 \mathrm{mM}$ hydroxylamine, $1 \mathrm{mM}$ ATP, $50 \mathrm{mM}$ glutamate, $20 \mathrm{mM} \mathrm{MgCl}_{2}$ and $20 \mathrm{mM}$ sodium arsenate. The mixture was incubated for 30 min at $37{ }^{\circ} \mathrm{C}$, and $1 \mathrm{~mL}$ of ferric chloride reagent was added $\left(0.37 \mathrm{M} \mathrm{FeCl}_{3}\right.$ and $0.2 \mathrm{M}$ trichloroacetic acid in $0.5 \mathrm{M} \mathrm{HCl}$ ). After centrifugation (5000 g for $15 \mathrm{~min}$ at $4{ }^{\circ} \mathrm{C}$ ), the absorbance was recorded at $520 \mathrm{~nm}$. The results were expressed as A per h per $\mathrm{g}$ fresh weight.

GDH activity assays were carried out according to Groat and Vance (1981). For the NADH-GDH activity measurements, the $1.9 \mathrm{~mL}$ reaction buffer contained $10 \mathrm{mM} \alpha$-oxoglutaric acid, $100 \mathrm{mM} \mathrm{NH}_{4} \mathrm{Cl}$ and 0.2 $\mathrm{mM}$ NADH in $50 \mathrm{mM}$ Tris- $\mathrm{HCl}$ buffer (pH 8.0), and the reaction started when $100 \mu \mathrm{L}$ of extract was added. For the NAD-GDH activity measurements, the reaction buffer consisted of $80 \mathrm{mM} \mathrm{L}$-glutamic acid and $0.2 \mathrm{mM} \mathrm{NAD}$ in $50 \mathrm{mM}$ Tris-HCl buffer (pH 8.8), and the reaction was initiated when $100 \mu \mathrm{L}$ of extract was added. The oxidation/reduction of NADH/NAD was measured by a UV-Vis Spectrophotometer (TU1901 UV-Vis Spectrophotometer, Purkinje General, Beijin, China) at $340 \mathrm{~nm}$ for $7-10 \mathrm{~min}$, and the 
activity of GDH in units of $\mu \mathrm{mol}$ of NADH oxidized/ $\mathrm{NAD}$ reduced per min per $\mathrm{mL}$ was calculated using an extinction coefficient for NADH at $340 \mathrm{~nm}$. The results were expressed as $\mu$ mol per min per $g$ fresh weight.

AlaAT activity assays were conducted according to Good and Muench (1992). The reaction buffer consisted of 15 $\mathrm{mM} \alpha$-oxoglutarate, $0.15 \mathrm{mM} \mathrm{NADH}, 0.5 \mathrm{M} \mathrm{L}$-alanine and 5 units lactate dehydrogenase in $50 \mathrm{mM}$ Tris- $\mathrm{HCl}$ buffer ( $\mathrm{pH}$ 7.5), and the reaction was initiated by adding $100 \mu \mathrm{L}$ of the enzyme extract. AspAT activity levels were assessed according to Griffith and Vance (1989). The $1.4 \mathrm{~mL}$ reaction buffer included $5 \mathrm{mM}$ EDTA, 0.2 M L-aspartate, $12 \mathrm{mM}$ 2-oxoglutarate, $0.15 \mathrm{mM} \mathrm{NADH}$ and 5 units malate dehydrogenase in $50 \mathrm{mM}$ Tris- $\mathrm{HCl}$ buffer ( $\mathrm{pH} 7.5$ ), and the reaction started when $100 \mu \mathrm{L}$ of the enzyme extract was added to the reaction buffer. AlaAT and AspAT activities were calculated using an absorption coefficient for NADH $\left(\varepsilon=6.22 \mathrm{mM}^{-1} \mathrm{~cm}^{-1}\right)$ and were expressed as the amount of enzyme required to form $1 \mu \mathrm{mol}$ of product per min per $\mathrm{g}$ of fresh weight.

\subsection{Statistical analysis}

The data are presented in the figures as the averages of at least three replicates per treatment and reported as the means \pm SD. Statistical significance was evaluated with Student's t-test, and considered to be significant when the $\mathrm{P}$ value was less than 0.05 .

\section{Results}

\subsection{Effects of copper stress on fresh weights and $N$ concentrations}

The effects of copper stress on the fresh weights and $\mathrm{NH}_{4}^{+}, \mathrm{NO}_{3}^{-}$and $\mathrm{NO}_{2}^{-}$concentrations of the Luffa cylindrica roots are shown in Figure 1. The fresh weights of the roots gradually decreased with increasing copper concentrations, showing measurements of $72.4 \%, 53.8 \%, 48.8 \%$ and $10.9 \%$ relative to the control at copper concentrations of $25,50,75$ and $100 \mu \mathrm{M}$, respectively (Figure 1A).
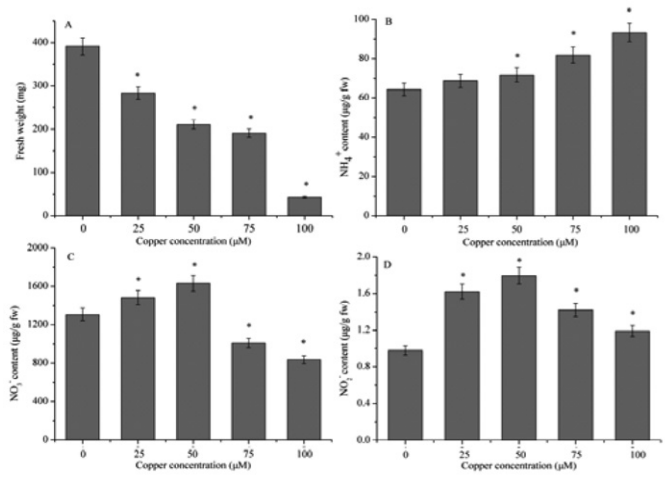

Figure 1. Effects of copper stress on fresh weights (A) and $\mathrm{NH}_{4}^{+}(\mathrm{B}), \mathrm{NO}_{3}^{-}(\mathrm{C})$ and $\mathrm{NO}_{2}^{-}$(D) concentrations in Luffa cylindrica roots. Data are displayed as means \pm standard deviations for three replications. Significant difference $(p<0.05)$ is denoted as asterisk $(*)$ between control and copper treatments.

Ammonium levels in the treated groups increased by $6.73 \%, 11.4 \%, 27.2$ and $45 \%$ relative to the control at copper concentrations of $25,50,75$ and $100 \mu \mathrm{M}$, respectively (Figure 1B). Nitrate concentrations in the roots were significantly induced by the 25 and $50 \mu \mathrm{M}$ copper treatments, but the values were inhibited by 75 and $100 \mu \mathrm{M}$ of copper (Figure $1 \mathrm{C}$ ). $\mathrm{NO}_{2}^{-}$concentrations showed increases of $165.5 \%, 183.2 \%, 145 \%$, and $121.6 \%$ relative to the control at copper concentrations of 25, 50, 75 and $100 \mu \mathrm{M}$, respectively (Figure 1D).

\subsection{Effects of copper stress on NR and NiR activities}

The effects of copper stress on the NR and NiR activities in the Luffa cylindrica roots are shown in Figure 2. NR activities were induced by $39.5 \%, 49.5 \%$ and $11.7 \%$ at copper concentrations of 25,50 , and 75 $\mu \mathrm{M}$; treatment with $100 \mu \mathrm{M}$ copper inhibited NR by $21 \%$ relative to the control (Figure $2 \mathrm{~A}$ ). As shown in Figure 2B, NiR activity levels gradually decreased with increasing copper concentrations, showing reductions of $15.6 \%, 36 \%, 44.3 \%$ and $49.2 \%$ relative to the control, respectively. 


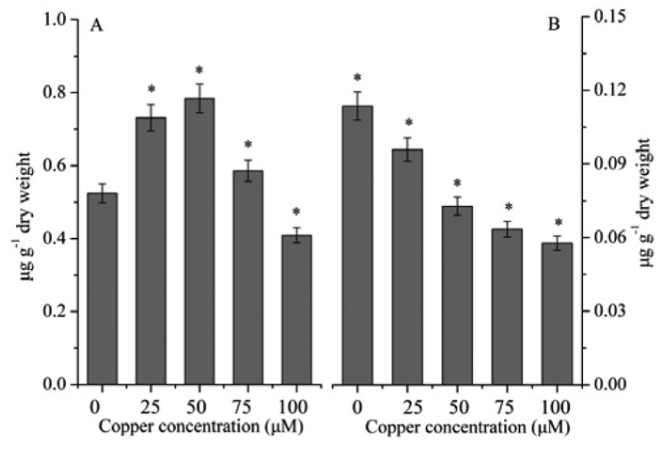

Figure 2. Effects of copper stress on nitrate reductase (A) and nitrite reductase (B) activities in Luffa cylindrica roots. Data are displayed as means \pm standard deviations for three replications. Significant difference $(p<0.05)$ is denoted as asterisk $(*)$ between control and copper treatments.

\subsection{Effects of copper stress on GS and GOGAT activities}

The effects of copper stress on the GS and GOGAT activities in the Luffa cylindrica roots are shown in Figure 3. As shown in Figure 3A, GS activity levels significantly increased by $105.7 \%, 90.3 \%, 54.6 \%$ and $52.7 \%$ relative to the control at copper concentrations of $25,50,75$ and $100 \mu \mathrm{M}$, respectively. As shown in Figure 3B, GOGAT activity levels increased by $102.1 \%, 157.8 \%, 92.6 \%$ and $31.9 \%$ relative to the control at copper concentrations of 25, 50, 75 and 100 $\mu \mathrm{M}$, respectively.

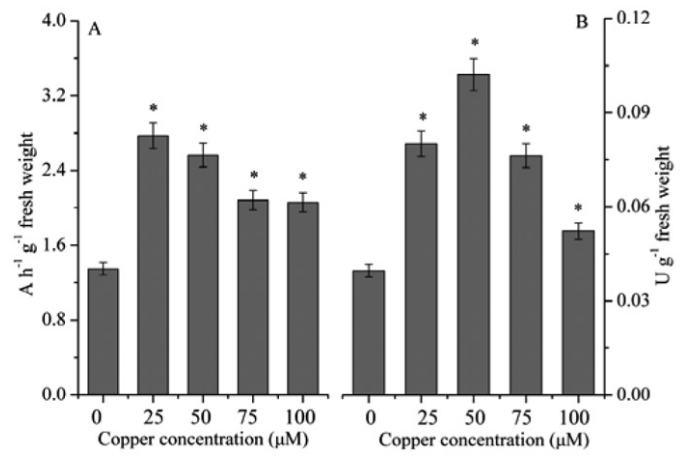

Figure 3. Effects of copper stress on glutamine synthetase (A) and glutamate synthase (B) activities in Luffa cylindrica roots. Data are displayed as means \pm standard deviations for three replications. Significant difference $(p<0.05)$ is denoted as asterisk $(*)$ between control and copper treatments.

\subsection{Effects of copper stress on GDH activities}

The effects of copper stress on GDH activities in the Luffa cylindrica roots are shown in Figure 4. As shown in Figure 4A, NADH-GDH activity levels in the roots increased significantly following the copper treatments, with values reaching $203.8 \%, 193.5 \%$ $178.6 \%$ and $161.1 \%$ of the control value at copper concentrations of $25,50,75$ and $100 \mu \mathrm{M}$, respectively. As shown in Figure 4B, NAD-GDH activity levels were significantly induced by copper concentrations of 25,50 , and $75 \mu \mathrm{M}$ but inhibited by $100 \mu \mathrm{M}$ copper.

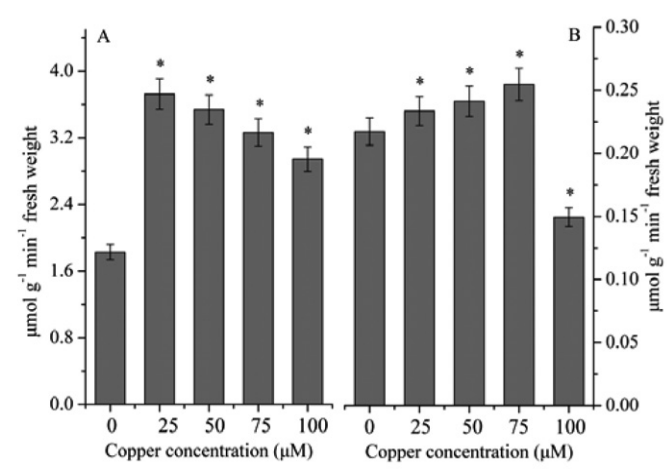

Figure 4. Effects of copper stress on NADH-glutamate dehydrogenase (A) and NAD-glutamate dehydrogenase (B) activities in Luffa cylindrica roots. Data are displayed as means \pm standard deviations for three replications. Significant difference $(p<0.05)$ is denoted as asterisk $(*)$ between control and copper treatments. 


\subsection{Effects of copper stress on AlaAT and AspAT activities}

The effects of copper stress on AlaAT and AspAT activities in the Luffa cylindrica roots are shown in Figure 5. As shown in Figure 5A, AlaAT activity levels at copper concentrations of 25,50 , and $75 \mu \mathrm{M}$ increased by $29.9 \%, 35.8 \%$ and $30.6 \%$ relative to the control values, but activity levels at the concentration of $100 \mu \mathrm{M}$ showed no change. As shown in Figure 5B, AspAT activity levels increased gradually with rising copper concentrations up to $75 \mu \mathrm{M}$, with the peak value being approximately $130.5 \%$ higher than that of the control.

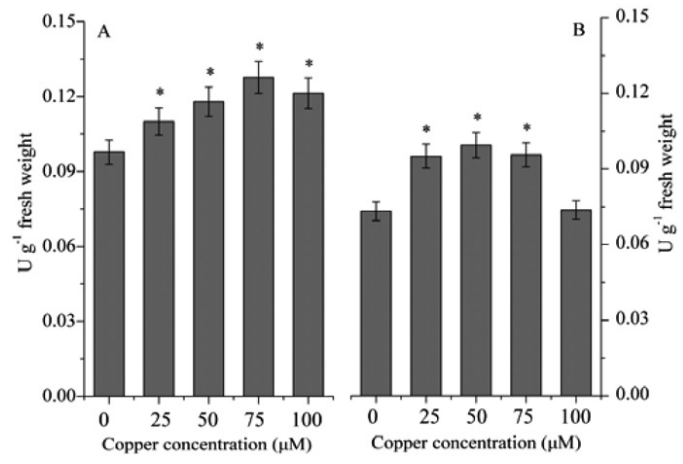

Figure 5. Effects of copper stress on alanine aminotransferase (A) and aspartate aminotransferase (B) activities in Luffa cylindrica roots. Data are displayed as means \pm standard deviations for three replications. Significant difference $(p<0.05)$ is denoted as asterisk $\left.{ }^{*}\right)$ between control and copper treatments.

\section{Discussion}

Heavy metals are prevalent abiotic stressors affecting plant growth and development. Growth inhibition is a common response to this type of stress, and plant growth is one of the most important agricultural indices of heavy metal stress tolerance, as has been indicated by numerous studies. Copper is an essential micronutrient for normal plant growth and metabolism, but it can be toxic to plants at higher concentrations (Yruela 2009). Excess copper has been reported to lead to the inhibition of young seedling growth and root elongation and to damage root epidermal cells and root cell membranes (Xiong and Wang, 2006; Lequeux et al., 2010). The present results suggest that there is a correlation between increasing copper concentrations and reduced root fresh weight (Figure 1A). N metabolism is a prerequisite for normal plant growth and development because almost all 'vital' biomolecules are nitrogenous substances (Mokhele et al., 2012). The forms and concentrations of $\mathrm{N}$ within a plant vary widely according to the organ, developmental stage, and environmental conditions. The root is obviously the predominant organ where many exchanges of a variety of $\mathrm{N}$ forms occur between root cells and the soil solution (Stitt et al., 2002). We show that the $\mathrm{NO}_{2}$ and $\mathrm{NH}_{4}^{+}$concentrations significantly increased in the Luffa cylindrica roots following the copper treatments, but the $\mathrm{NO}_{3}{ }^{-}$concentrations were inhibited at 75 and $100 \mu \mathrm{M}$ copper (Figure 1). The present findings seem to contradict those from previous reports, which have suggested that $\mathrm{NO}_{3}^{-}, \mathrm{NO}_{2}^{-}$and $\mathrm{NH}_{4}^{+}$concentrations in leaves are significantly reduced by heavy metal stresses in tobacco, and spinach plants (Wu et al., 2008; Maaroufi Dguimi et al. 2009). These changes may be a combined result of the inhibition of the uptake and transport of $\mathrm{NO}_{3}{ }^{-}$along with the decreased activities of NR and NiR (Figure 2).

In plant cells, nitrate is reduced to ammonium through a two-step process. The first is the reduction of nitrate to nitrite, which is catalyzed by NR, and the second is the reduction of nitrite to ammonium by NiR (Stitt et al., 2002). Several studies have shown that changes in the concentrations of different $\mathrm{N}$ forms are correlated with the activities of NR and NiR in tobacco and spinach plants that have been exposed to heavy metal stress. Moreover, decreases in NR and NiR activities have been observed in plants due to their breakdown as induced by the ROS that are generated following heavy metal stress (Xiong et al., 2006). The present findings suggest that the higher copper concentrations of 75 
and $100 \mu \mathrm{M}$ result in decreased levels of NR activity, and concentrations of $25-100 \mu \mathrm{M}$ also lead to reduced levels of NiR activity. These changes may be related to the reductions in the $\mathrm{NO}_{3}^{-}$and $\mathrm{NO}_{2}^{-}$concentrations that occurred at copper concentrations of 75 and 100 $\mu \mathrm{M}$ (Figure 1).

The primary pathway for the entry of ammonium into amino acids is the GS/GOGAT cycle, which involves the sequential actions of GS and GOGAT (Figure 3). Biochemical, genetic and molecular evidences have shown that the major pathway for ammonia assimilation into organic molecules is the GS/GOGAT cycle in higher plants (Stitt et al., 2002). There is also evidence that alternative routes for assimilating ammonium may be triggered when GS activity is impaired (Skopelitis et al. 2006). The present results indicated that the activities of GS and GOGAT increased to varying degrees relative to those of the controls. These findings appear to differ from those of other studies addressing the GS/GOGAT cycle. Thus, additional studies are required to examine these conflicting results. An alternative pathway for $\mathrm{N}$ assimilation may involve the direct reductive amination of $\alpha$-ketoglutarate by the GDH. This enzyme catalyzes a reversible reaction that synthesizes (NADH-GDH) or deaminates (NADGDH) glutamate in vitro (Stitt et al., 2002). GDH is ubiquitous in plants and is often present at high levels in plant tissues, including both senescing tissues and root tissues (Ludewig et al., 2007). This enzyme can operate in either the assimilation or the reassimilation of ammonium, thereby complementing the enzymes of the GS/GOGAT cycle in glutamate synthesis, especially under stressful conditions such as elevated temperatures, water, salinity, pollution and heavy metals (Skopelitis et al. 2006). Recent data from studies of transgenic tobacco plants with altered GDH genes revealed that all GDH isoenzymes strongly deaminate glutamate, and only the anionic GDH isoforms exhibit very low aminating activities under normal trophic conditions (Skopelitis et al. 2007). The findings from the present work suggested that varying increases in the activities of NADH-GDH and NADGDH occurred following all copper treatments with the exception of $10 \mu \mathrm{M}$ copper. Thus, this study has provided insight into the tissues that show variable GDH activity levels in response to elevated copper concentrations. Aminotransferases, including AlaAT and AspAT, can catalyze the reversible transfer of an amino group from glutamate to pyruvate to form 2-oxoglutarate and alanine/aspartate. Their regulation in several plant species has been studied in response to heavy metal stress (Gajewska et al., 2009; Mishra and Dubey, 2011). Thus, these two enzymes may be reasonable targets for metabolic engineering to produce crop varieties with enhanced stress resistance capabilities and nutrient concentrations. As shown in Figure 5, the activities of AlaAT and AspAT in the roots were significantly induced by the copper treatments. Thus, in our experiment, increases in AlaAT and AspAT activities in the plant tissues may indicate a detoxification response to copper exposure.

\section{Conclusions}

In conclusion, the results of this study support the hypothesis that copper is toxic to Luffa cylindrica, which is at least partially due to the influences of copper on $\mathrm{N}$ metabolism and on enzymes associated with $\mathrm{N}$ metabolism. We hope that these findings will contribute to the improved understanding of the response mechanisms of Luffa cylindrica to copper stress and lend further insight into metal-microbe interactions in natural environments. We believe that future studies using copper treatments for longer exposure times will aid in the elucidation of the $\mathrm{N}$ nutrition- and metabolism-related changes that occur following exposure to copper toxicity in Luffa cylindrica.

\section{Acknowledgments}

This work was supported by National Natural Science Foundation of China (No 51309170 and No. 51379136). 


\section{References}

Agbaria, H., Heuer, B., Zieslin, N. 1996. Shootroot interaction effects on nitrate reductase and glutamine synthetase activities in rose (Rosa $\times$ hybrida cvs. Ilseta and Mercedes) graftlings. Journal of Plant Physiology. 149, 559-563.

Azmat, R., Khan, N. 2011. Nitrogen metabolism as a bioindicator of $\mathrm{Cu}$ stress in Vigna radiata. Pakistan Journal of Botany, 43, 515-520.

Bouazizi, H., Jouili, H., El Ferjani, E. 2007. Copperinduced oxidative stress in maize shoots (Zea mays L.): $\mathrm{H}_{2} \mathrm{O}_{2}$ accumulation and peroxidases modulation. Acta Biologica Hungarica. 58, 209 218.

Debouba, M., Gouia, H., Suzuki, A., Ghorbel, M.H. 2006. $\mathrm{NaCl}$ stress effects on enzymes involved in nitrogen assimilation pathway in tomato "Lycopersicon esculentum" seedlings. Journal Plant Physiology. 163, 1247-1258.

Gajewska, E., Wielanek, M., Bergier, K., Sklodowska, M. 2009. Nickel-induced depression of nitrogen assimilation in wheat roots. Acta Physiologiae Plantarum. 31, 1291-1300.

Gao, S., Yan, R., Cao, M., Yang, W., Wang, S., Chen, F. 2008. Effects of copper on growth, antioxidant enzymes and phenylalanine ammonia-lyase activities in Jatropha curcas L. seedling. Plant, Soil and Environment. 54, 117-122.

Good, A.G., Muench, D.G. 1992. Purification and characterization of an anaerobically induced alanine aminotransferase from barley roots. Plant Physiology. 99, 1520-1525.

Griffith, S.M., Vance, C.P. 1989. Aspartate aminotransferase in alfafa root nodules. I. Purification and partial characterization. Plant Physiology. 90, 1622-1629.
Groat, R.G., Vance, C.P. 1981. Root nodule enzymes of ammonia assimilation in alfalfa (Medicago sativa L.). Plant Physiology. 67, 1198-1203.

He, X., Li, J. 2010. Effects of cadmium toxicity on some growth parameters and antioxidant enzymes in Luffa cylindrica seedlings. Fresenius Environmental Bulletin. 11, 2630-2636.

Lequeux, H., Hermans, C., Lutts, S.,Verbruggen, N. 2010. Response to copper excess in Arabidopsis thaliana: Impact on the root system architecture, hormone distribution, lignin accumulation and mineral profile. Plant Physiology and Biochemistry. 48, 673-682.

Losada, M., Paneque, A. 1971. Nitrite reductase. Methods in Enzymology. 23. 487-491.

Ludewig, U., Neuhäuser, B., Dynowski, M. 2007. Molecular mechanisms of ammonium transport and accumulation in plants. FEBS Letters. 581, 2301-2308.

Maaroufi, Dguimi., H, Debouba, M., Ghorbel, M.H., Gouia, H. 2009. Tissue-specific cadmium accumulation and its effects on nitrogen metabolism in tobacco (Nicotiana tabaccum, Bureley v. Fb9). Comptes Rendus Biologies. 332, 58-68.

Mishra, P., Dubey, RS. 2011. Nickel and Al-excess inhibit nitrate reductase but upregulate activities of aminating glutamate dehydrogenase and aminotransferases in growing rice seedlings. Plant Growth Regulation. 64. 251-261.

Mokhele, B., Zhan, X., Yang, G. Zhang, X. 2012. Review: Nitrogen assimilation in crop plants and its affecting factors. Canadian Journal of Plant Science. 92, , 399-405.

Molins-Legua, C., Meseguer-Lloret, S., MolinerMartinez, Y., Campíns-Falcó, P. 2006. A guide for selecting the most appropriate method for 
ammonium determination in water analysis. Trends in Analytical Chemistry. 25, 282-290.

Oaks, A., Stulen, I., Jones, K., Winspear, M.J., Misra, S., Boesel, I.L. 1980. Enzyme of nitrogen assimilation in maize roots. Planta. 148, 477-484.

Rachina, M.A., Nicholas, D.J.D. 1985. Glutamine synthetase and glutamate synthase from Sclerotinia sclerotiorum. Phytochemistry. 24, 2451-2548.

Skopelitis,D.S.,Paranychiankis, N.V.,Paschalidis,K.A., Plianokis, E.D., Delis, I.D., Yakoumakis, D.I., Kouvarakis, A, Papadakis, A, Stephanou, E.G, Roubelakis-Angelakis, K.A. 2006. Abiotic stress generates ROS that signal expression of anionic Glutamate dehydrogenase to form Glutamate for proline synthesis in tobacco and grapevine. Plant Cell. 18. 2767-2781.

Skopelitis, D.S., Paranychiankis, N.V., Kouvarakis, A., Spyros, A., Stephanou, E.G., RoubelakisAngelakis, K.A. 2007. The isoenzyme 7 of tobacco NAD(H)-dependent Glutamate dehydrogenase exhibits high deaminating and low aminating activity. Plant Physiology. 145, 1-9.

Stitt, M., Müller, C., Matt, P., Gibon, Y., Carillo, P., Morcuende, R., Scheible, W.R., Krapp, A. 2002. Steps towards an integrated view of nitrogen metabolism. Journal of Experimental Botany. 53, 959-970.
Werber, M.M., Mevarech, M.1978. Purification and characterization of a highly acidic $2 \mathrm{Fe}$-ferredoxin from Halobacterium of the Dead Sea. Archives of Biochemistry and Biophysics. 187, 447-456.

Wu, X., Liu, C, Qu, C, Huang, H, Liu, X, Chen, L, Su, M., Hong, F. 2008. Influences of lead (II) chloride on the nitrogen metabolism of spinach. Biological Trace Element Research. 121, 258265.

Xiong, Z.T., Liu, C.,Geng, B. 2006. Phytotoxic effects of copper on nitrogen metabolism and plant growth in Brassica pekinensis Rupr. Ecotoxicology and Environmental Safety. 64, 273-280.

Yang, Y., Ma, X., Wu, W., Guo, P. 1999. Biological characters of the different varieties for Luffa cylindrica. Zhong Yao Cai. 22, 165-167.

Yruela, I. 2009. Copper in plants: acquisition, transport and interactions. Functional Plant Biology, 36, 409-430. 